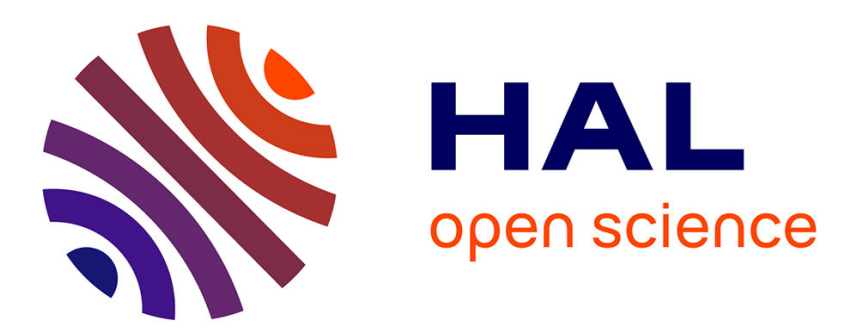

\title{
A fully automated technique for the rapid assessment of uniformity of doped layers by the four point probe method
}

\author{
B.J. Smith, J. Stephen
}

\section{- To cite this version:}

B.J. Smith, J. Stephen. A fully automated technique for the rapid assessment of uniformity of doped layers by the four point probe method. Revue de Physique Appliquée, 1977, 12 (3), pp.493-501. 10.1051/rphysap:01977001203049300 . jpa-00244202

\section{HAL Id: jpa-00244202 https://hal.science/jpa-00244202}

Submitted on 1 Jan 1977

HAL is a multi-disciplinary open access archive for the deposit and dissemination of scientific research documents, whether they are published or not. The documents may come from teaching and research institutions in France or abroad, or from public or private research centers.
L'archive ouverte pluridisciplinaire HAL, est destinée au dépôt et à la diffusion de documents scientifiques de niveau recherche, publiés ou non, émanant des établissements d'enseignement et de recherche français ou étrangers, des laboratoires publics ou privés. 


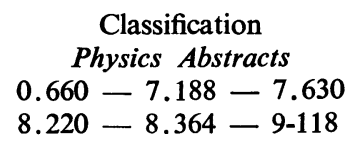

\title{
A FULLY AUTOMATED TECHNIQUE FOR THE RAPID ASSESSMENT OF UNIFORMITY OF DOPED LAYERS BY THE FOUR POINT PROBE METHOD
}

\author{
B. J. SMITH and J. STEPHEN \\ Electronics and Applied Physics Division, AERE Harwell, Oxfordshire OX11 0RA U.K.
}

(Reçu le 18 octobre 1976, accepté le 24 novembre 1976)

\begin{abstract}
Résumé. - La mesure de l'uniformité du dopage d'un semiconducteur par la méthode de quatre pointes a été réalisée. Quelques imperfections de cette méthode sont décrites et des améliorations sont proposées. Il est en particulier démontré qu'avec des précautions convenables, la fidélité de la mesure est supérieure à un pour cent.

La technique décrite utilise un système automatique de déplacement et de mesure. Les données sont analysées par un calculateur pour tracer directement les profils de résistivité. Quelques exemples d'applications de cette technique sont donnés pour mettre en évidence les processus conduisant à des dopages non uniformes.
\end{abstract}

\begin{abstract}
A measurement procedure based on the four point method has been used for the assessment of semiconductor doping uniformity. Some of the causes of inaccuracy in four point probe measurements are discussed and methods of reducing the effects are described. It is demonstrated that provided suitable precautions are taken during the measurement, the reproducibility of measurement is better than one percent.

The technique described uses automated measurement and wafer scanning equipment. Data is analysed by computer to derive maps of the sheet resistance variations. Uses of the technique to show processing induced non uniformities in doped layers are discussed and some examples are shown.
\end{abstract}

1. Introduction. - In recent years improved semiconductor doping techniques have permitted controlled doping over large areas. Uniformity of doping is important for circuits containing high value resistors (MacDougall et al. [1]) ; MOSTs requiring controlled threshold voltage shifts (Aubuchon [2] ; doped regions known as tubs or wells for complementary MOS circuitry (Dill et al. [3]) ; and buried $\mathrm{n}^{+}$layers for bipolar structures (Chisholm et al. [4]) and many other applications. Failure to control the doping concentration accurately and maintain a high degree of uniformity in such devices can seriously reduce the yield. Uniformity is also an essential requirement in the manufacture of large area position sensitive radiation detectors and semiconductor vidicon arrays.

This paper describes a convenient method of measuring the uniformity of doping of circular silicon wafers. The method uses the sheet resistance of the doped layer as an indication of the impurity concentration. The two techniques normally used for the measurement of sheet resistance use either fabricated resistors or a four point probe. Hitherto the four point probe has been regarded as suitable only for approximate indication of average sheet resistance. Seirmarco [5] describes the accuracy of the technique as about six percent. The alternative method involves the fabrication of an array of identical resistors over the surface of the wafer. Figures $1 a$ and $b$ show two alternative structures for such resistors. Both structures require two doping steps and aluminisation and etching steps. These steps are time consuming and therefore expensive.

In this paper we describe a method of using the four point probe to give an accurate and rapid measurement of mean sheet resistance and the variation over the wafer. Also described is the data collection system and method of computer analysis used to construct doping uniformity maps.

2. Wafer preparation. - The four point probe measurement requires a minimum of wafer preparation. The wafer is doped, using normal methods, over the whole area. Doping methods that have been used include diffusion, ion implantation, and epitaxial growth. Also wafers have been measured in which no additional doping has been added since the crystal was grown. Normally the doping would be of the opposite 


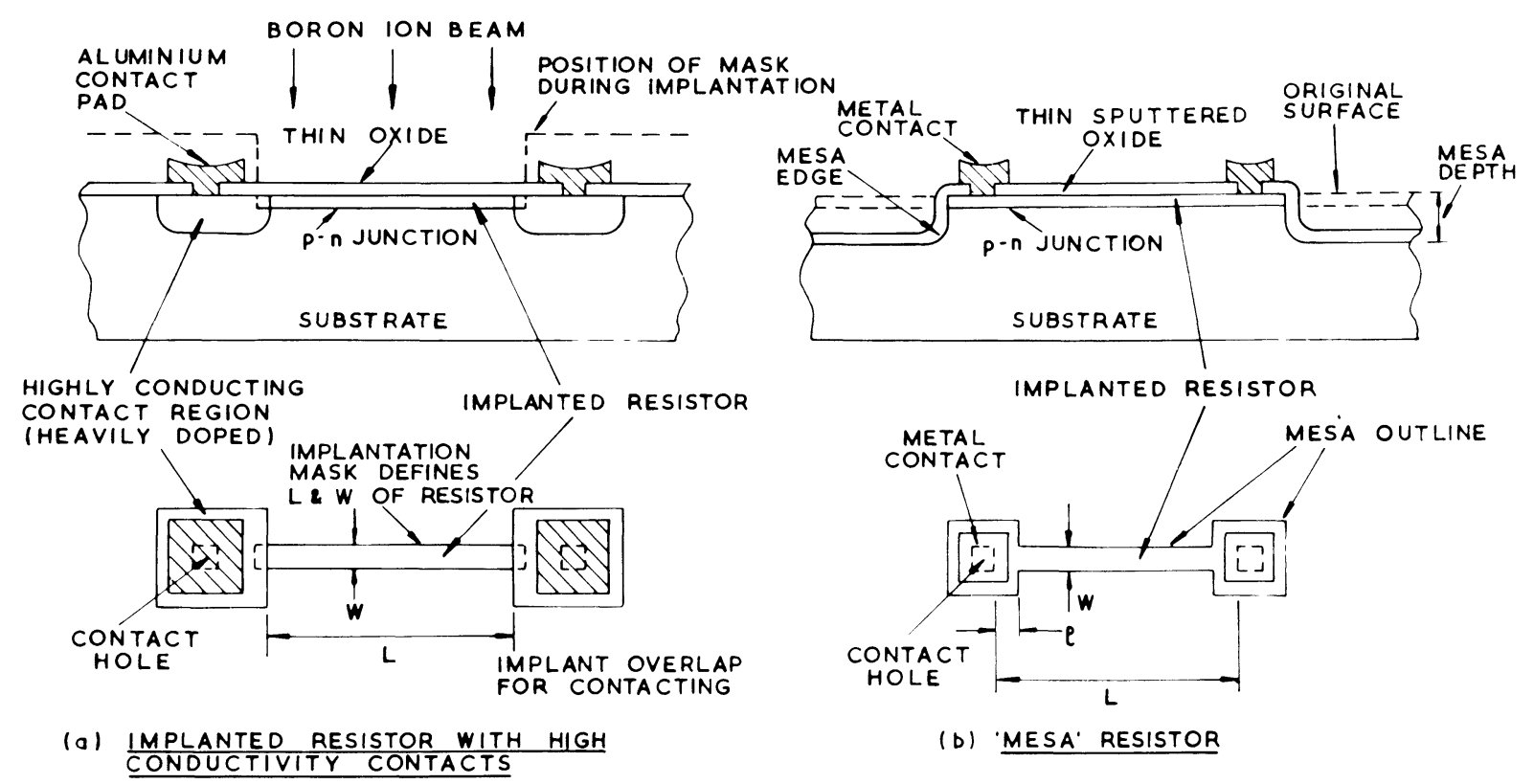

FIG. 1. - a) Planar structure of an ion implanted resistor; $b$ ) Mesa structure of an ion implanted resistor.

doping type to that of the original wafer. However, when high resistance wafers have been used the doping has been of either type. This has been particularly useful when it has been required to assess the uniformity of buried layers such as those produced by very high energy ion implantation.

After doping and any treatment required to activate the dopant such as a high temperature anneal of an implanted layer, the only wafer preparation that is required is to ensure that the surface is clean. Wafers are washed in buffered hydrofluoric acid to remove any oxide traces and then in deionised water and isopropyl alcohol.

3. Measurement techniques. - It has been found necessary to take a number of precautions in order to ensure an accurate measurement. These precautions are discussed below.

3.1 WAFER DAMAGE. - Measurements have been made on silicon wafers with a Fell in-line four point probe assembly. Two such assemblies have been used. The first had a needle force of $200 \mathrm{gms}$; the second had a force of $20 \mathrm{gms}$. The heavy probe could only be used on thick doped layers. With layers thinner than about $1500 \AA$ the probe damaged the surface and penetrated the doped layer to contact the substrate underneath. Figure 2 shows typical damage that has been produced by the $200 \mathrm{gm}$ probe. This photograph, taken in a scanning electron microscope, was of a wafer held onto the probing platform by vacuum. Without the vacuum the wafer moved freely on the cushion of air beneath it as the probe was lowered onto it and the damage was even more severe.

With the 20 gm probe no damage could be observed and it was possible to make measurements on thin ion

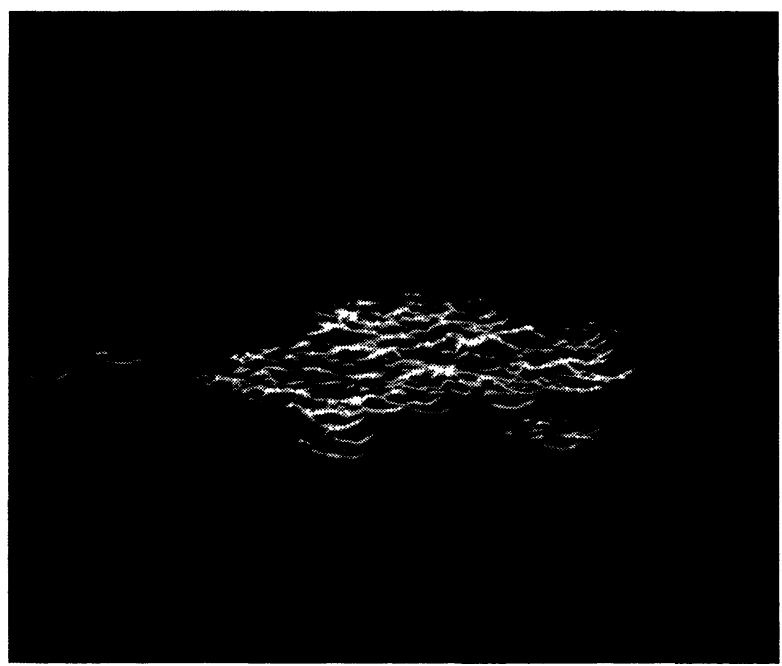

FIG. 2. - Damage produced by $200 \mathrm{gm}$ four point probe.

implanted layers less than $400 \AA$ thick without difficulty if the wafer was held firmly by vacuum onto the probing table.

3.2 Probe Contact forming. - During the measurement a pre-selected current flows through the outer two probes. This current flow helps to ensure that a good ohmic contact is produced between the outer probes and the silicon. In order to make the same good contact between the inner probes and the wafer the current is initially switched through these inner probes for about $200 \mathrm{~ms}$ before the measurement begins. Without this forming procedure the voltage measured across the inner probes was found to vary. 
3.3 REVERSE CURRENT FLOW. - Normally measurements have been made with the current flow in one direction only. However, periodic checks are made to ensure that with the current direction reversed the measured sheet resistance remains unchanged. Possible causes of unequal measurements are damage to the probe needles or the guides, uneven probe pressure or uneven illumination of the wafer. In order to eliminate the last possibility the measurements were carried out in a dark enclosure.

3.4 Measurement CurRent. - The current flowing in the wafer during the measurement is supplied by a Bradley 132 D. C. calibrator. This instrument has a current output range $10^{-6}-10^{-2} \mathrm{~A}$. Normally the current used is kept to a minimum in order to minimise the heating effects in the wafer and to keep the voltage drop between the probes to a minimum. A large voltage between the probes will cause a variation in the depletion width associated with the $\mathrm{p}-\mathrm{n}$ junction isolating the doped layer. A varying depletion width can cause a significant change in the thickness of the conducting layer especially for lighly doped layers, and consequently in its resistance. The current is normally chosen so that it produces a measurable voltage between the inner pair of four point probes. As the voltmeter used is a digital instrument with a $10^{-5} \mathrm{~V}$ resolution, the measurement current is adjusted to give approximately $3 \times 10^{-3} \mathrm{~V}$ readings. This then permits $0.33 \%$ resolution. Alternatively the measurement current $I$ can be expressed in terms of the sheet resistance, $\mathbf{R}$ as

$$
I \simeq 0.014 / R
$$

3.5 MEASUREMENT CONTROL CIRCUITRY. - Figure 3 shows a shematic layout of the measurement controller.
The measurement sequence is initiated by a TTL level « 1 » signal from the current supply. The constant current supply unit has an under-current indicator lamp which is illuminated when the pre-set current cannot be supplied. A signal from this indicator has been obtained via an opto-isolator device to avoid interfering with current supply circuitry. The under-current condition exists whilst the 4 point probe unit is not in contact with the wafer. When the probe is lowered the signal level switches to " $1 »$ and remains at this level unless the current flow is interrupted by a poor probewafer contact. Such poor contacts can sometimes occur on high resistance silicon. When good contact is again established the transition from « 0 » to « 1 » allows the measurement sequence to continue.

The controller comprises a number of 555 type timer circuits, each producing a level « $1 »$ output for the duration of the pre-set period and the transition black to level « 0 » triggers the next timer in the sequence. The timing sequence is :

1. Contact forming $(200 \mathrm{~ms})$.

2. Measurement settling period (1 s).

3. Measurement trigger pulse $(100 \mathrm{~ms})$.

4a. Current reverse (period of $4 b$ plus $100 \mathrm{~ms}$ ).

4b. Measurement settling period (1 s).

5. Measurement trigger pulse $(100 \mathrm{~ms})$.

6. Output pulse to initiate probe raise and wafer movement (1 s).

Interruption of the current flow during periods 2 or $4 b$, resets the timer by shorting the timing capacitors ( $\mathrm{C}$ in Fig. 3) and the period recommences when the current flow is re-established.

The sequence can be interrupted after periods 2 and $4 b$ to allow additional time for the voltmeter to settle. This mode of operation is only used for very high

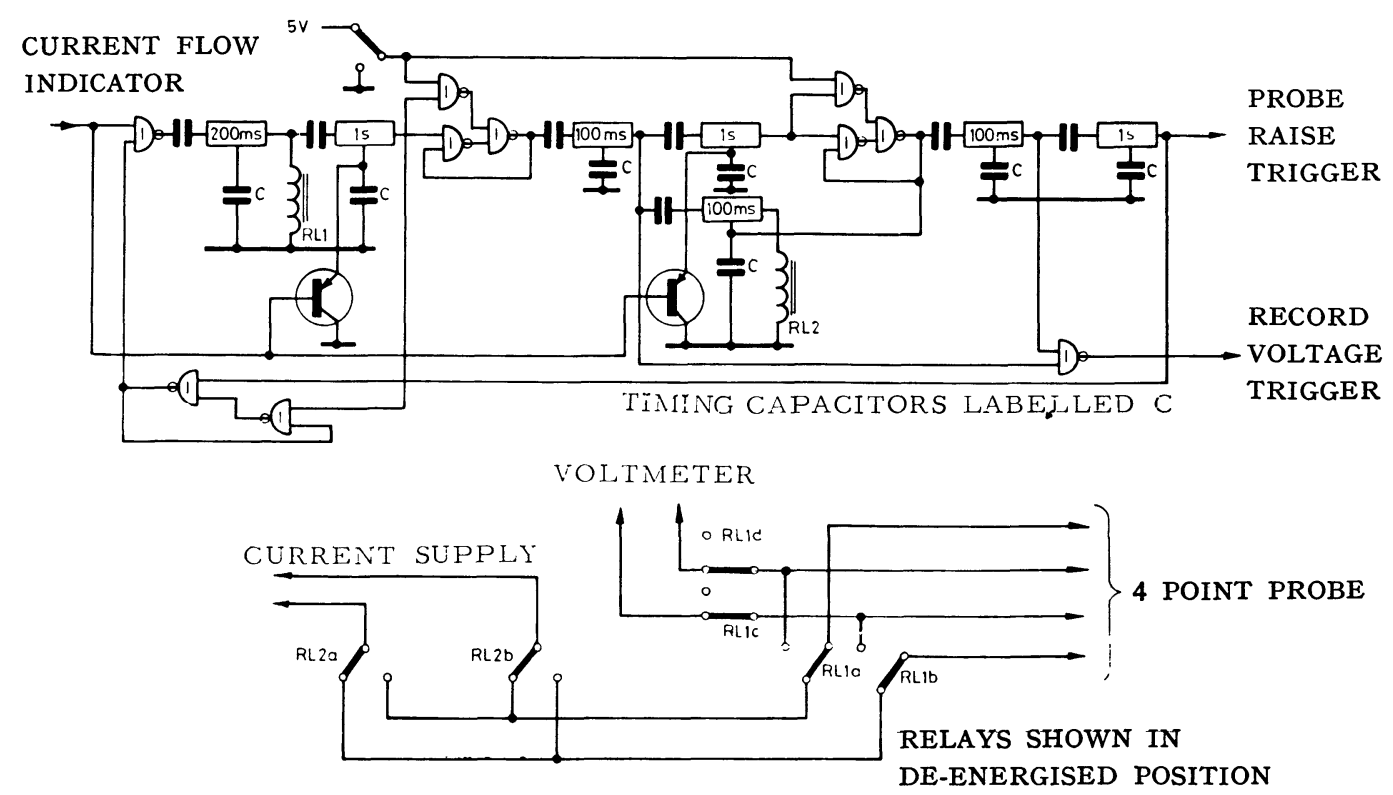

FIG. 3. - Measurement control circuit. 
resistance wafers and the sequence has to be restarted manually.

The current is switched by reed relays to the probe needles.

3.6 WAFER TRANSPORT. - In order to make measurements over the whole of the wafer, it is moved under the probe. As the data is to be interpreted using existing relationships it is essential that the line of the probe needles lies either along or at right angles to the radius. In the present work the latter geometry was used. This is ensured by using only radial and rotary movements of the wafer. The arrangement used is shown schematically in figure 4 . The two movements are driven by stepping motors. The linear drive across the wafer diameter is at a rate of $1 \mathrm{~mm}$ per 200 steps and the rotary movement is at a rate of $1^{\circ}$ per 50 steps. A stepping controller shown schematically in figure 5 moves the wafer under the probe head in preset steps across a wafer diameter. The radial drive then rotates the wafer so that a different diameter is measured on the return pass. Switched controls permit steps of 1,2 or $4 \mathrm{~mm}$ across a 32,36 or $40 \mathrm{~mm}$ diameter. This scanned diameter is for use with two inch diameter wafers. Preset switches can be set for 3 or 4 inch wafers which simply multiply linear measurement by 1.5 or 2.0 times. The probes cannot be lowered whilst either stepping motor is operating. Additional protection

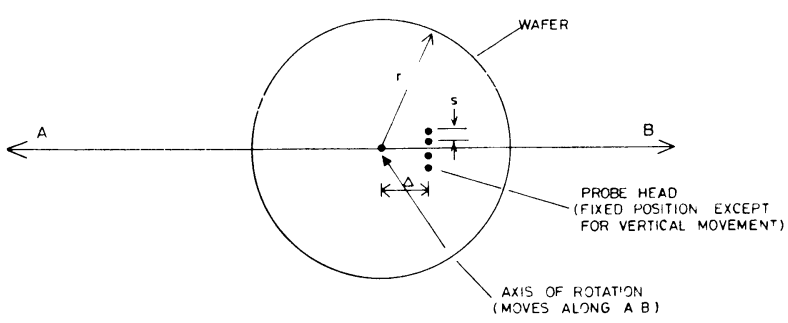

FIG. 4. - Position of the probe on a wafer.

against accidental wafer movement whilst the probe is lowered is provided by microswitches situated above the probe mechanism.

Inputs to the controller are from a start switch on the front panel and from the end of measurement pulse from the measurement controller. The start of this pulse raises the probe and the end of the pulse actuates the wafer movement. The outputs from the controller switch the two stepping motor oscillators on and off and change the direction. The oscillator and the logic used to switch the current to the motor coils is not shown as they use standard circuit techniques.

The vertical movement of the probe head is controlled by a vacuum piston and a solenoid valve.

Figure 6 shows the equipment. It comprises the stepping arrangement, and the probe raising and

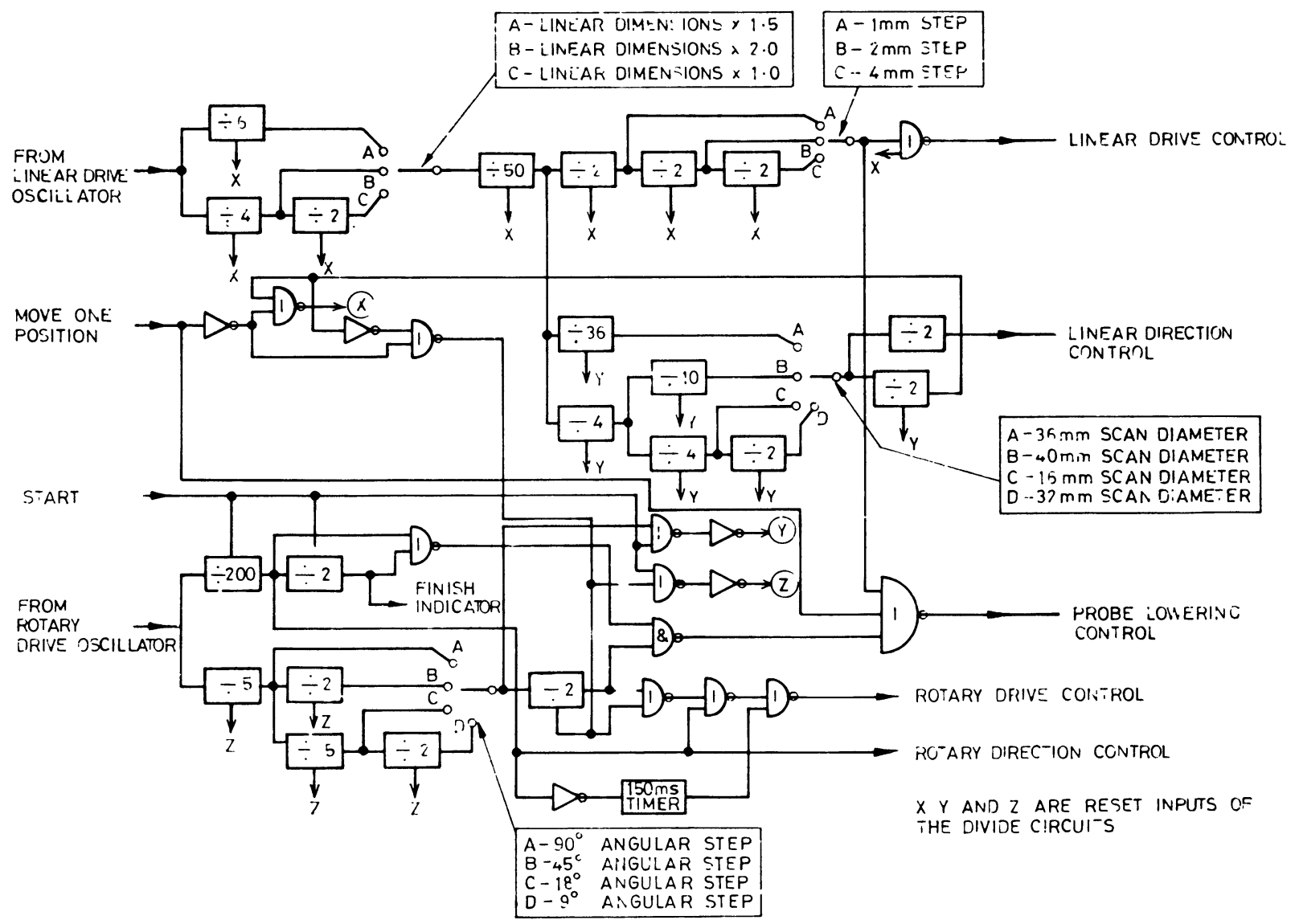

Fig. 5. - Wafer stepping control circuit. 


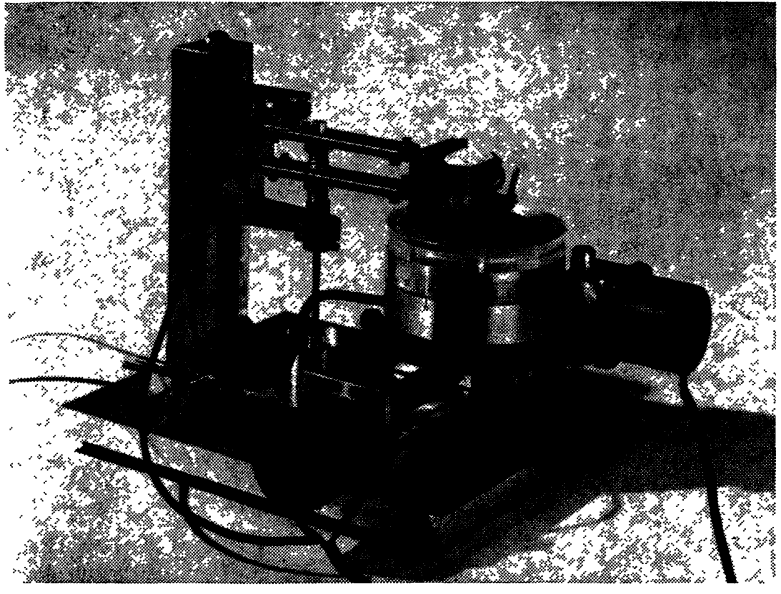

FIG. 6. - The measurement equipment.

lowering mechanism. It has been removed from the dark box for this photograph.

4. Data analysis. - The voltages displayed on the digital voltmeter were recorded on 8 hole punched paper tape. Also recorded on the tape were the spacing of the probe needles, diameter of the wafer, incremental spacing of the steps between measurements, and measurement current. These were entered via a keyboard. A computer program was written to analyse the data recorded on the paper tape.

At the centre of a large wafer the relationship between measurement current $I$, recorded voltage $V$ and sheet resistance $R$ is given by

$$
R=K \times \frac{V}{I}
$$

where $K=4.523$.

At other places on the wafer the constant $K$ has a different value which depends on the distance from the centre, the diameter of the wafer and the spacing of the probe needles. For the two simple cases where the line joining the needles lies either along a radius or at right angles to it the value of $K$ can be calculated from the equations of Logan [6] or Schwartzendruber [7]. For the probe at right angles to the radius, as shown in figure 4, the value of $K$ is calculated as

$$
K=\frac{\pi}{(1+\eta) \ln 2}
$$

where

$$
\begin{aligned}
\eta & =\frac{1}{2 \ln 2} \ln \frac{\alpha_{1} \alpha_{2}}{\alpha_{3} \alpha_{4}} \\
\alpha_{1} & =\left(V_{2}-V_{1}\right)^{2}+\left(U_{1}+U_{2}\right)^{2} \\
\alpha_{2} & =\left(V_{2}+V_{1}\right)^{2}+\left(U_{1}+U_{2}\right)^{2} \\
\alpha_{3} & =\left(V_{2}-V_{1}\right)^{2}+\left(U_{2}-U_{1}\right)^{2} \\
\alpha_{4} & =\left(V_{2}+V_{1}\right)^{2}+\left(U_{2}-U_{1}\right)^{2}
\end{aligned}
$$

$$
\begin{aligned}
& U_{1}=\frac{3 s r}{D_{1}} \\
& U_{2}=\frac{s r}{D_{2}} \\
& V_{1}=\frac{1-\left(\frac{\Delta}{r}\right)^{2}-\frac{9}{4}\left(\frac{s}{r}\right)^{2}}{D_{1}} \\
& V_{2}=\frac{1-\left(\frac{\Delta}{r}\right)^{2}-\frac{1}{4}\left(\frac{s}{r}\right)^{2}}{D_{2}} \\
& D_{1}=\left(1+\frac{\Delta}{r}\right)^{2}+\frac{9}{4}\left(\frac{s}{r}\right)^{2} \\
& D_{2}=\left(1+\frac{\Delta}{r}\right)^{2}+\frac{1}{4}\left(\frac{s}{r}\right)^{2}
\end{aligned}
$$

$s$ is the spacing of the probe needles,

$r$ is the radius of the wafer, and

$\Delta$ is the distance between the probe and the centre of the wafer. The dimensions are shown on figure 4 .

The sheet resistance for each measurement is calculated using the appropriate value of $K$. Values outside preset limits are rejected and the mean of the remainder calculated. The standard deviation $\sigma$ of $N$ values from the mean is given by

$$
\sigma=\sqrt{\sum_{1}^{N} \frac{(R-\bar{R})^{2}}{N}}
$$

and it can be expressed as a percentage of the mean value $\bar{R}$ as ; \% standard deviation $=\sigma \times 100 / \bar{R}$. In the analysis it must be remembered that more points are recorded close to the centre of the wafer than near the perimeter. For this reason an increased weighting is applied to the outside points in the calculation of the mean value and its deviation. The weighting factor is calculated by considering the wafer to be divided into regions with a measurement point at the centre of each. The boundaries of each region are the locii of points equidistant from the two nearest measurement positions. Then the weighting, $w$, for each measurement is taken to be proportional to the area of the appropriate region. The absolute value of $w$ is calculated so that its average value is unity.

In order to show how the sheet resistance changes over the wafer a contour map of sheet resistance is drawn. Iso-resistance contours are normally drawn for each percentage deviation from the mean. These are generated by dividing the area of survey into a number of sections with a measurement position at each of the four corners. As the measurement positions are in a polar matrix the sections are trapezoidal. Each section is subdivided into four triangles by the diagonals. The value of sheet resistance assigned to the intersection of the diagonals is the mean of the four corner values. Interpolating linearly between the values at the corners 
of a triangular section determines the points at which any of the defined contours cross the boundaries of the section. The contour is thus uniquely plotted across the section. Within a triangular section the contour is plotted as a straight line. In order to distinguish between the different contours the lines are chain dotted with the mark space ratio increasing for higher resistance contours. Contours corresponding to resistances more than two standard deviations below the mean are dotted with a minimum mark space ratio. More than two standard deviations above the mean the contours are continuous. Within two standard deviations of the mean the gradation between these two extremes is progressive. On the contour map the measurement positions are marked with crosses.

5. Application of the techniques. - This technique has been used for the measurement of the uniformity of doping of silicon wafers by ion implantation and by thermal diffusion. For ion implanted specimens no difficulty has been experienced working in the range 10 to $2000 \Omega$ per square. Above this range measurements were less reproducible but useful measurements have been made on specimens up to $20 \mathrm{k} \Omega$ per square. Measurements have been made on very thin layers without breaking through to contact the underlying substrate. Such layers have been made by implanting $40 \mathrm{keV}$ arsenic ions into silicon. The estimated thickness of such a layer is $0.03 \mu$. A number of measurements have been made on diffused specimens in the range 3 to $1000 \Omega$ per square. No difficulty was experienced with the measurements. Such layers were usually less uniform than implanted layers.

Measurements have also been made on the uniformity of undoped wafers and epitaxial layers. Nonuniformity of epitaxial doping or thickness shows up as a non-uniformity in sheet resistance. The technique has been used to study the effect of annealing ion implanted specimens and to observe changes in distribution of sheet resistance during the annealing process. As no metallic contacting techniques are required it is a simple matter to follow the annealing behaviour of a wafer over a wide range of annealing temperatures. It is usual to protect or cap the doped wafer surface with a

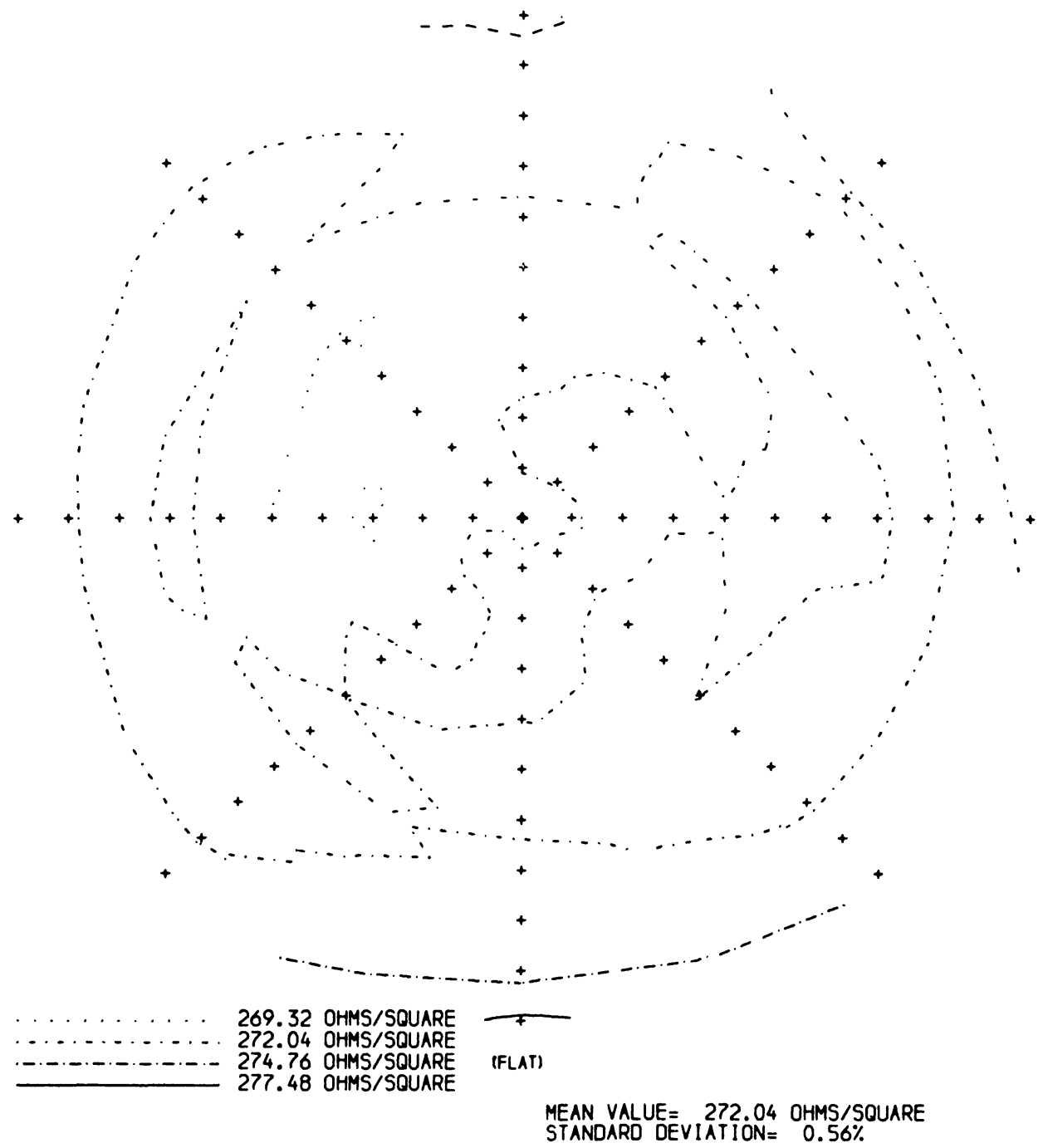

FIG. 7. - Sheet resistance distribution of a uniformly ion implanted wafer. 
layer of radio frequency sputtered silicon dioxide which is readily removed in buffered hydrofluoric acid after annealing. The uniformity of oxidation processes have been studied by measurement of the uniformity of an implanted and annealed silicon wafer after the oxide has been removed.

6. Example of results. - The three examples shown have been chosen to demonstrate the potential uses of the technique and the accuracy of the measurement. All examples are of measurements on two inch diameter wafers.

The first example in figure 7 shows an ion implanted wafer and is typical of measurements made on carefully prepared specimens. The specimen was implanted on the Lintott Series III ion implantation machine with $3.2 \times 10^{14}$ boron ions per $\mathrm{cm}^{2}$ at $40 \mathrm{keV}$. The implantation and subsequent thermal processing was carried out in a manner most likely to produce uniform activa- tion of the boron impurities. The requirements for uniform activity are discussed by Freeman et al. [8]. This example shows that with a uniform layer the technique produces uniform results. It is noted that although the wafer is very uniform the higher value is in clearly defined areas suggesting that non uniformities are still present. Random measurement errors would not produce such a distribution. The standard deviation of $0.6 \%$ is therefore due partly to measurement uncertainty with some small contribution from non uniformities in the implanted layer or in the thermal activation of the impurity during annealing. This result is consistent with the observations of Bullis [9] who reported $0.3 \%$ reproducibility in the mean of several measurements. However, it is inconsistent with the accuracy reported by Seirmarco. Seirmarco [5] reported the accuracy of the technique as being about $6 \%$.

In the second example shown in figure 8 a layer

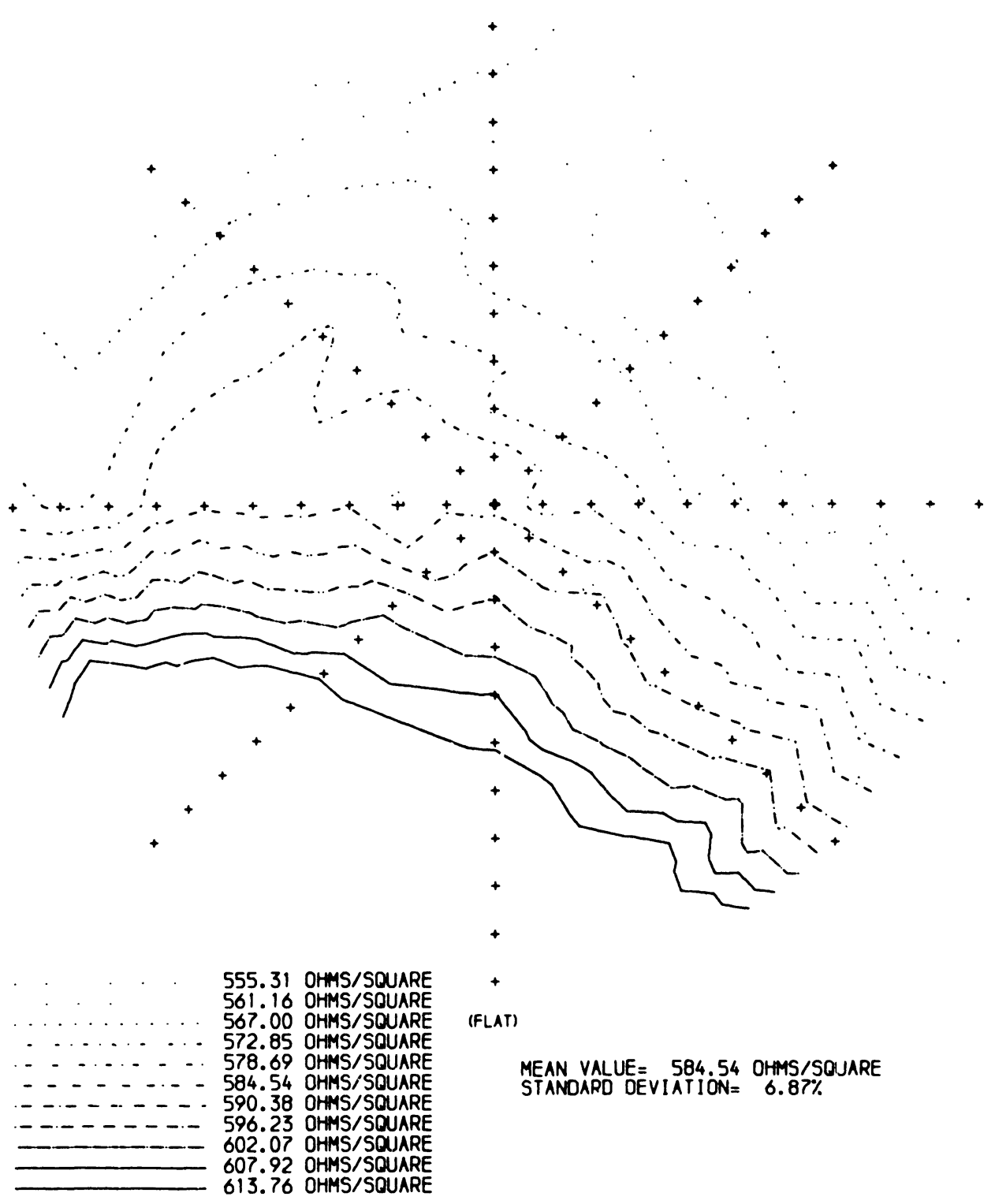

FIG. 8. - Sheet resistance distribution of an ion implanted wafer showing the effect of uneven heating during implantation. 


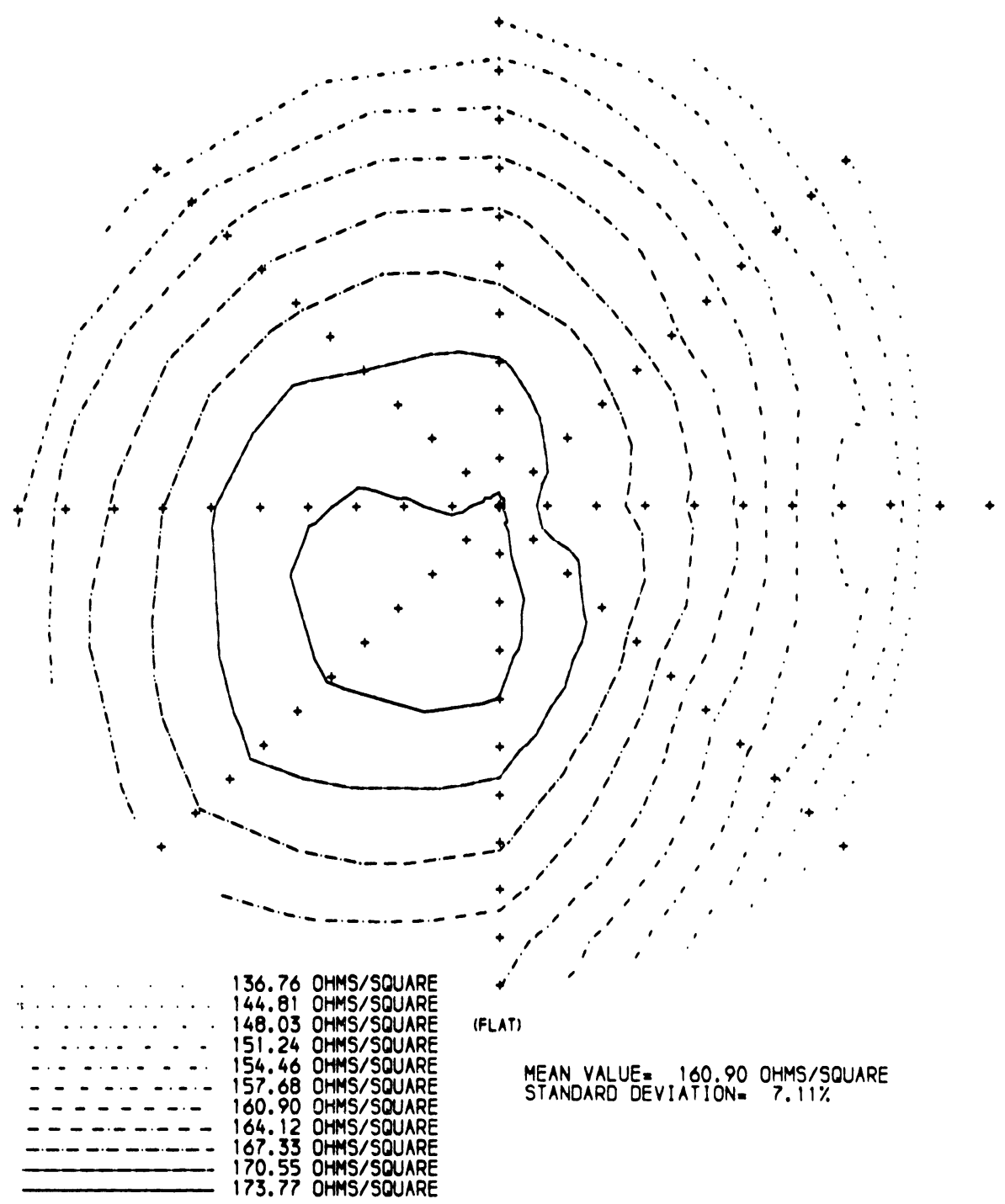

FIG. 9. - Sheet resistance distribution of an arsenic diffused wafer.

uniformly implanted with $1 \times 10^{15}$ boron ions per $\mathrm{cm}^{2}$ at a sufficiently fast rate to produce significant wafer heating has been measured after annealing at $600{ }^{\circ} \mathrm{C}$. The variation in sheet resistance across the wafer is attributed to thermal gradients during the implantation.

The third example in figure 9 shows an arsenic diffusion from an arsine gas source. The $n$ type layer was formed on a p substrate. It is clear that the low resistance region close the edge has been caused by a high arsine vapour pressure near the edge of the wafer. During the diffusion, wafers were stacked with the faces vertical behind one another in a row along the furnace tube. Apparently the wafers were too close together to allow adequate flow of the dopant arsine between them. In this example the conducting layer extended around the back of the wafer and Logan [6] has shown that this condition can be treated as an infinite plane with a single value of $K$ (see eq. (4.1)). However, it should be noted that the total variation in sheet resistance shown in figure 4 of more than $20 \%$ is much larger than any possible variation in the value of $K$. Therefore the circular pattern observed in this wafer could not be attributed to the choice of constants used in the data analysis.

7. Conclusions. - It has been shown that provided care is taken to clean the wafer, minimise probe contact resistance, eliminate ambient illumination, minimise the probe pressure, and apply the necessary corrections for the position of the probe on the wafer, the four point probe can be a satisfactory way of measuring wafer doping uniformity. The procedure described is quick and accurate to better than one percent over a large doping range. By adopting a graphical display of the measurements it has been possible to use the technique to observe defects in the processing schedule of wafers.

Acknowledgements. - The authors are pleased to acknowledge the collaboration of many colleagues at Harwell during the preparation of this paper. In parti- 
cular they wish to thank G. Gard for implantations, E. M. Wittam for the wafer preparation and G. W. Hin- der for helpful discussions at the commencement of the work.

\section{References}

[1] MacDougall, J. D., Manchester, K. E. and Roughan, P. E., Proc. IEEE, 57 (1969) 1538.

[2] Aubuchon, K. G., Proc. Int. Conf. Properties and uses of M. I. S. structures, Grenoble, p. 575 (1969).

[3] Dill, N. G., Toombes, T. N. and Bauer, L. O., Proc. 2nd Int. Conf. Ion Implantation, Garmish (pub. Springer Verlag), p. 315, 1971.

[4] Chisholm, J., Stephen, J., Turner, J., Dobson, P., FranCis, R. and Williams, B., Proc. 4th Int. Conf. Ion Implantation, Osaka (pub. Plenum), p. 641, 1974.
[5] Seirmarco, J. A., Electrochem Soc. Extended Abstract, No 152 (1973) 73-2.

[6] Logan, M. A., Bell Syst. Techn. J., 40 (1961) 885.

[7] SWartzendruber, L. J., Solid State Electron. 7 (1964) 413.

[8] Freeman, J. H., Chivers, D. J., Gard, G. I., Hinder, G. W., Smith, B. J. and Stephen, J., Proc. 4th Int. Conf. Ion Implantation, Osaka (pub. Plenum Press), p. 555, 1974.

[9] Bullis, W. M., NBS Report 9666 (1967). 